as an evil, at the same time that it prevents the bones being fixed in the compressed position in which they would be if the splint or bandage were applied while the patient was standing or sitting.

Avoiding occupying valuable space with the remarks which I made on the necessity for some addition to the usually employed means of treating angular curvature of the spine, and the uselessness of the various mechanical appliances, \&c., I quote verbatim only the rules which I laid down to enable o hers to apply the bandage as successfully as I had done. I said, "The desiderata in an apparatus which is to aid the object aimed at in laying the patient recumbent seem to be these $:-1$. Such an apparatus must relieve the diseased vertebræ of the pressure caused by the weight of the trunk and upper limbs. 2. It must tend to fix the bones of the spine, and prevent all movement, whether rotatory or of any other kind, such as that implied in raising the body from the bed to perform any office of nature, or in the movement implied in carriage exercise, \&c. 3. It must be light and comfortable to the patient, and it should be obtainable at a cost which brings it within reach of the poor, among whom we are less able to enforce the treatment by recumbency, and who are consequently more dependent upon such mechanical contrivances." Pointing out that the thorax being more or less barrel-shaped, its lower part forming a portion of an inverted cone-an instrument resting firmly on the hips and presenting upwards, as it were, a conical cup into which it received the trunk, would carry the weight of the chest, head, and sboulders, I said :- "The most efficient splint thus will be one which approaches as nearly to this form as is compatible with the health and comfort of the patient; a complete girdle of solid material forming a section of an inverted cone fitted to the lower part of the thorax would, however, be so con. fining that it could not be borne, and as the girdle must have a certain amount of elasticity, and must not be solid throughout, it is necessary that that part which is solid should be adapted with absolute accuracy to the chest, fitting close to any irregularities of the surface, such as the margin of the ribs, \&c., which give additional points of support. All the points indicated as desirable are, I think, possessed by the simple gutta-percha splint or corset, which I have employed with the greatest benefit in almost every case of angular curvature of the spine which I have treated since 1863. The points to be attended to in its construction, and on which its utility will depend, are the following:-1. The material must be sufficiently strong. 2. The size of the splint must be such that it is $(a)$ supported on the hips, not by its edge, but by being moulded to the pelvis; (b) it must extend upwards so as to reach quite to the upp $+\mathrm{r}$ dorsal vertebræ, being cut away under the axilla; and $(c)$ it is quite essential that it should be so wide as to lap round and embrace the sides of the thorax beyond the angles of the ribs (the front edges should be separated only by two or three inches); unless it does so it will merely act as a splint applied to the back, and cannot be regarded as a section of an inverted cone, in which character alone, as I have already stated, can it be looked upon as in any measure relieving the spine of the weight of the shoulders. 3. It must be very accurately moulded to the body, especial care being taken to press it well in at the waist, so as to ensure the conical form of the upper part. 4. The splint, when finished, must admit of being well laced in front, so as to make it act as a complete girdle."

The directions which I give for the application of the splint are as follows:-1st. To ensure sufficient strength, employ a sheet of gntta-percha of the thickness of about a quarter of an inch. 2nd. Take the following measurements: (a) from the sacrum to the vertebra prominens, for the height of the splint; (b) round the back of the pelvis from a point about an inch anterior to the spine of the ilium to the corresponding point on the opposite side, to give the width at the lower edge; and (c) round the back of the thorax from about the situation of the nipple to the corresponding point on the opposite side, to give the width of the upper part of the splint. Cut out the gutta-percha in accordance with these measurements, allowing a margin for its shrinking when warmed, and cut away the top edge so as to admit of its passing under the arm. 3rd. To ensure an accurate mould, the patient should be stripped and seated at the edge of a feather bed; three or four strips of flannel, from four to five inches wide, and long enough to surround the patient's body and cross in front, are to be arranged like a many-tailed bandage, their edges overlapping about an inch, and laid across a feather bed, so that when the patient lies down he should rest upon them. The guttapercha, softened in water at a temperature of about $135^{\circ}$. should be lifted out of the water on a sheet of wash-leather, and laid carefully on the strips of flannel, the uncovered surface down wards and the chamois-leather upwards. The patient, who should be seated on the edge of the bed with the lower edge of the gutta-percha close to his hips, is now laid down with his back upon it, care being taken that the spine corresponds to the middle of the splint, and that its lower edge is as low as the sacrum. The gutta-percha must then be rapidly folded round the bips, waist, and chest. being, while still soft, pressed well in at the waist; the strips of flannel are brought round and fastened tightly with pins down the front of the body, the strip round the waist being drawn specially tight. All these steps must bo taken very promptly, as the gutta-percha, of course, rapidly cools. 4th. When the splint is hard, the pins are removed。 the splint taken off and trimmed up where it may be re. quired, a front attached to it with eyelets on each side, so that it may be tightly laced down the front of the body, and to the middle of the top edge of the splint are attached two brace-straps, which cross over the shoulders and buckle in front."

I wish to add to the remarks with which I have prefaced the above quotations, that by careful atiention to the some. what minute details which I have enumerated, any medical man can readily apply this apparatus, and that the position of the patient on his back while the splint is applied does all that suspending the patient for the plaster-of-Paris bandage can safely and beneficially effect. I believe, then, that the gutta-percha support, open down the front, is preferable to the complete girdle of plaster-of-Paris advocated by Mr. Barwell; but should the latter be selected, wonld suggest that the best mode of applying it would be by placing a many-tailed bandage such as I use, but several folds thick, well soaked in gum and chalk, on a soft bed: on this the patient should lie as I have directed for the application of the gutta-percha case, the tails of the bandage being folded closely over, and allowed to set before tho patient moves.

\section{RUPTURE OF THE UTERUS WITHOUT SYMPTOMS.}

BY RICEMOND LEIGH, M.R.C.S., ASSISTANI YCEDICAL OFFICRR TO THE LXING-IX FOSPITAL, LIVERPOOT.

MrS. G- began to be in labour with her ninth child about 2 P.M. on Feb. 26th. About 10 P.M. I was sent for by the midwife who was attending her, on accuunt of the labour not progressing, as, according to her account, the child had been in the same position for about five hours. On examination, I found the breech of a female child presenting at the brim of the pelvis, the pains strong, yet failing to cause any advance. Placing my hand upon the abdomen, I was surprised to feel an arm of the child, as it were, beneath the abdominal wall, the fingers even being quite distinguishable, so plainly could it be perceived. The probability of rupture of the uterus immediately presented itself to me, although there were no symptoms of collapse (save the pulse being small), the pains continuing vigorous. I attempted to bring down a foots but the strength of the pains and the position of the child - wedged, as it were, in the brim of the pelvis-prevented my succeeding. Dr. Pierce (whom I had sent for) therefore administered chloroform, and I then succeeded in bringing down first one foot and then the other. There was some little farther difficulty in bringing down the arms, whioh had passed up on either side of the head; and, finally, the forceps had to be applied and considerable force used to deliver the head.

The pains continued good to the termination of labour, and the placenta came away easily. On now examining, a rent in the lower and anterior part of the uterns was found, through which the hand could easily be passed and the uterus grasped in the abdominal cavity. The rupture was 
transverse, and situated a little above the os, thus leaving the body of the womb entire. The arm had evidently escaped through the rent, the head remaining, and the position of the tear permitted uterine pains to continue. The intestines did not come down, nor were even felt by me. The uterus contracted fairly, without much hæmorrhage. A binder with compress was firmly applied, opium given freely, and brandy in small quantities repeatedly. There was still no collapse.

The next day (27,h) she expressed herself as feeling tolerably well, but a chronic bronchitic cough troubled her a good deal, and she vomited occasionally. There was pain in the abdomen, but not much tenderness, and the lochia were moderate. A small quantity of urine was removed by the catheter, and bismuth solution and hydrocyanic acid ordered with the opium.

28th.-Vomiting ceased since last night; tongue brownish and dry; slightly delirious; has passed urine; breathing sort and quickened. During the day, contrary to instructions, she was moved to "change the bed," after which considerable bamorrhage occurred. In the evening she was much lower, "pain had gone," and the breathing was very" hort and quick.

March 1st.-Died at 4 A.M.

This case is remarkable in several respects, chiefly in the absence of symptoms of collapse and the continuance of the pains till the completion of the labour. I was with her over an hour and a half, and the rupture may have occurred aeveral hours earlier. On inquiring into her history, I found that her previous labours had been normal, but tedious. About four months ago she had hurt herself lifting a mangle, but was not laid up by the injury. Possibly this may have caused some inflammatory change or adbesions, and thus have been the cause of rupture when labour came on.

I obtained a partial post-mortem examination, and found the rent lying open, the body of the uterus fairly contracted, but drawn away from the lower margin of the rupture. The nterine substance was normal, but the upper part of the vagina was more fixed than usual, and there was some recent effusion of lymph. From the hurried and limited examination allowed, I was not able to do it satisfactorily.

The rupture was at about the junction of the upper two thirds with the lower third of the uterus.

Siverpool.

\section{A}

\section{HOSPITAL PRACTICE, BRITISH AND FOREIGN.}

Nulla antem est alia pro certo noscendi via, nisi quamplurimas et morborum t dissectionum historias, tum aliorum, tum proprias collectas habere, et inter so compararo.-MorgaGI De Sed. et Caus. ARorb., lib. iv. Procemium.

\section{G U Y'S H O S P I T A L.}

CASES OF DYSPHAGTA.

(Under the care of Mr. BRyant.)

Thr subjoined notes complete the series of cases of dys. phagia which were commenced a fortnight ago. These are respectively the twenty-third and the twenty-fourth recorded cases in which the operation of gastrostomy has been performed for malignant disease of the ossophagus. We hope to be able at an early date to supply our readers with references to all the other recorded cases.

CASE 6. Stricture of the csophagus from syphilitic ulceration in a tubercular subject; gastrostomy; death on sixth day (130 hours) after operation, from pneumonia.-Thomas G-, an intemperate man, aged forty-eight, was admitted on syphilis when twenty jears of age, but there had been no symptoms since. Four months before admission he had zore-throat, which rapidly became worse, so that he was soon unable to take solid food, and for three months he had suffered pain in the right side of the neck. Cough had been troublesome for three weeks. During the four months he had lost twenty-eight pounds in weight.

On admission he was much emaciated and pale, his roice was feeble, and the breath offensive; any attempt to swallow caused great pain, and the food was always at once ejected through the nose and mouth. The palate was erquisitely sensitive, and on that account no laryngoscopic examination could be made, but with the finger passed well down the throut behind the larynx a hard swelling could be felt. The man was ordered to be fed by nutrient enemata every four hours, and for some days he seemed under this treatment to improve, but soon the enemata returned, and as swallowing was still impossible, the operation of gastrostomy was decided upon, in a consultation between Dr. Hahershon and Mr. Bryant.

Nov. $24 \mathrm{rh}$ - The operation was performed by Mr. Bryant under chloroform. The line of incision was oblique, just below the border of the left ribs, starting from the left semilunar line, and measured three inches in length. The stomach was readily picked up with the finger and thumb, and then opened and secured to the margins of the wound by means of the quill sutures. No difficulties were experienced in the operation. No food was introduced into the stomach for twenty-four hours, but nutrient enemata were given. On the next day a mixture of milk and egga was introduced into the stomach through the artificial opening, and the man appeared to rally, but the progress was not steady. On the fourth day he became delirious, and on the sixth he sank, having survived the operation 130 hours.

At the post-mortem examination, the artificial mouth, situated one inch to the left of the semilunar line, was found to have been perfectly established, the stomach being firmly fixed to the integument, and looking healthy. No signs of peritonitis were to be seen. At the posterior part of the pharynx, and extending downwards, an oval indolent ulcer was seen, two inches long, and nearly sur. rounding the canal, half an inch of mucous membrane behind the larynx alone remaining. The ulcer was hard, but had no raised edges; its base rested on altered muscle. On the larynx (its left side) was a small ulcer raised on a thickening, which was great in proportion to the ulcers. This thickening extended along the hinder two-thirds of that side of the larynx, and had the character of syphilitic larynx. The apex of the right lung was occupied by phthisical cavities, and these were of two dates. There were yellow, cheesy masses, and cavernons hollowing round, or partly round, some of these, so that flakes of the cheesy matter were crumbling into the said cavities. The lower three-fifths of the lung were in a state of red and grey hepatisation, the grey patches being small portions and scattered, the red filling in the intervals. The upper part offered this difference, that the patches were red hepatisation, the intervening tissue being nearly natural. The left lung contained $t$ wo softening patches of pneumonic tubercles, looking not unlike pyæmic patches. There was no ulceration in the ileum; great injection of the mucous membrane, no mucus on surface; passive injection. The colon had a large quantity of fæcal matter in its whole length. Gallbladder contained two ounces of dark bile in the cyst. The kidneys weighed 6 줄 oz., dark, small, and healthy-looking. The brain weighed $45 \frac{1}{2} \mathrm{oz}$. The scalp was thickened in the anatomical proportions uniformly.-Cranial bones: Slight irregularity of surface to left of middle line.-Arachnoid: Moderate thickening of membrane on upper surface.

CASE 7. Cancerous stricture of cesophagus; gastrostomy; death in twenty hours from acute bronchitis. (Reported by Mr.Giblin.) -Jos. C- a potato dealer, aged fifty three, was admitted into Naaman ward on the 10th September, 1872. Married, and the father of nine children. He had kept a beer-shop, and drank and smoked a good deal. He had a severe attack of quinsy three years and a half before admission; and a year before admission he got wet through and had an attack of sciatica in his left thigh and hip, and at the same time a constriction of the throat which interfered with his swallowing; he had noticed, however, some weeks before, a rattling in his throat when he drank. He was seen by a medical man, who tried to pass a tube down the throat, but failed. There was no history of venereal disease. He had lost flesh very much, and could take but little food, and that only in a liquid form; indeed, he had not taken solid food for forty weeks before admission. He was very thin, and looked ill. The patient's father and mother died at eighty-four years of age. His mother's sister died of some 